\section{THE LIQUEFACTION AND SOLIDIFICATION OF ARGON.1}

Having been furnished, by Prof. Ramsay's kindness, with a sample of the new gas, argon, I have carried out experiments on its behavinur at a low temperature and at high pressures, in order to contribute, at least in part, to the knowledge of the properties of this interesting body.

Four series of experiments in all were carried out, two with the object of $d$ termıning the critical temperature and pressure of argon, as well as measuring its vapour pressure at several other low temperatures, while two other series served to determine its hoiling and freezing points under atmospheric pressure, as well as its density at its boiling point.

A detailed description of the e experiments will be given in another ,lace; I shall here give only a short description of the manner in which they were made.

For the first two experiments I made use of a Cailletet's apparatus. Its metallic manon eter had been previously com pared with the rearlings of a mercury manometer. As cooling agent I used liquid erhylene, boiling under diminished pressure. The glass tube of Cailletet's appararus was so arranged that the portion immersed in the liquid ethylene had comparatively thin walls (not exceeding I $\mathrm{mm}$.), so as to equalise the external and internal temperalure as quickly as possible.

In both the other experiments the argon was contained in a burette, closed at both endr with glass stop-cocks. By connecting the lower end of the burette with a mercury reservoir, the argon was iransferred into a narrow glass tuhe fused at its lower end to the upper end of the burette, and in which the argon was liquefied, and its volume in the liquid state measured. In these two sertes of experiments liquid oxygen, boiling under atmospheric or under diminished pressure, was employed as a cooling agent. I made use of a hydrogen thermometer in all these exprriments to measure low temperatures.

\section{Determination of the Critical Constants of Argon.}

As soon as the temperalure of liquid ethylene had been lowered $t,-128^{\circ} \cdot 6$, the arginn eavily condensed to a colourless liquid under a pressure of $38 \mathrm{~atm}$ spheres. On slowly raising the temperature of the ethylene, the meniscus of the liquid argon became less and less distiuct, and finally vanished.

Seven determinations of the disappearance of the meniscus proved that the critical preisure was 506 atmospheres; but determinations of the critical temperature show slight differences. quadruple walls, so as to isolate the liquid from external heat. After the liquid oxygen har been thus poured under atmospheric pressure, a great part of it evaporated, but there still remained about 70 c.c. boiling under atmospheric pressure. A calibrated tube, intended to receive the argon to be liquefiel, and the hydrogen thermometer were immersed in the boiling oxygen. At thi: temperature $\left(-182^{\circ} \cdot 7^{1}\right)$ on admitting argon, no appearance of liquefaction could be n.sticed, even when compressed by adding a quarter of an atmosphere pressure to that of the atmosphere. This shows that its boiling point lies below that of oxygen. But on diminishing the temperature of the liquid oxygen below $-187^{\circ}$, the liquefaction of argon became manifest. When liquefaction had taken place, I carefully equalised the pressure of the argon with that of the atmosphere, and regulated the temperature, so that the state of balance was maintained for a long time. This process gives the boiling point of argon under atmospheric pressure. Four experiments gave the numbers $-186^{\circ} \cdot 7,-180^{\circ} \cdot 8,-187^{\circ} \circ$, and $-187^{\circ} \cdot 3$. The mean is - I $86^{\circ} .9$, which I consider to be the boiling point under atmospheric pressure $(740.5 \mathrm{~mm}$.).

The quantity of aryon used for these experiments, reduced to $\mathrm{n} \cdot \mathrm{rmal}$ temperature and pressure, was $99^{\circ} 5 \mathrm{c.c}$. ; the quan. tity of liquid corresponding to that voluune of yas was approximately O'Ir4 c.c. Hence the density of argon at is boiling point may be taken as approximately I'5. Two other determinations of the density of liquid argon, for which I t mployed s'ili smaller quantities of the gas, yielded rather smaller numbers. Owing to the small amount of argon used for these experiments, the numbers given cannot lay ciaim to great exaciness; yet they prove that the density of liquid argon at its boiling point $\left(-187^{\circ}\right)$ is much higher than that of oxygen, which $I$ have found, under similar conditions, to be $I \cdot 124$.

By lowering the temperature of the oxygen to $-191^{\circ}$ by slow exhaustion, the argon froze to a crystalline mass, resem. bling ice; on further lowering temperature it became white and opaque. When the temperature was raised it melted; four observations which $I$ made to determine its melting point gave the numbers: $-189^{\circ} \circ,-190^{\circ} \cdot 6,-189^{\circ} \cdot 6$, and $-189^{\circ} 4$. The mean of these numbers is $-189^{\circ} 6$; and this may be accepted as the melting point of argon.

In the following table I have given a comparison of physical constants, in which those of argon are compared with those of oih'r so called permanent gases. The data are from my previous work on the subject.

\begin{tabular}{|c|c|c|c|c|c|c|c|c|c|c|}
\hline Name. & & & $\begin{array}{c}\text { Critial } \\
\text { temperature. }\end{array}$ & $\begin{array}{l}\text { Critical } \\
\text { pressure. }\end{array}$ & $\begin{array}{l}\text { Boiling } \\
\text { point. }\end{array}$ & $\begin{array}{l}\text { Freezing } \\
\text { point. }\end{array}$ & $\begin{array}{l}\text { Freezing } \\
\text { pressure. }\end{array}$ & $\begin{array}{l}\text { Density } \\
\text { of gas. }\end{array}$ & $\begin{array}{l}\text { Density of } \\
\text { Liquid at } \\
\text { bulling } \\
\text { point. }\end{array}$ & $\begin{array}{l}\text { Colour of } \\
\text { liquid. }\end{array}$ \\
\hline & & & Delow. & Atmos. & & & $\mathrm{mm}$. & & & \\
\hline Hydrogen $\left(\mathrm{H}_{2}\right) \ldots$ & $\cdots$ & $\cdots$ & $-220^{\circ} 0$ & $20^{\circ} 0$ & $?$ & $?$ & $?$ & $1 \cdot 0$ & ? & Culourless. \\
\hline Nitrogen $\left(\mathrm{N}_{2}\right) \quad \ldots$ & $\cdots$ & $\cdots$ & -146.0 & $35^{\circ} \circ$ & $-194^{\circ} 4$ & $214^{\circ} \mathrm{O}$ & 60 & $14^{\circ} \mathrm{O}$ & 0.885 & , \\
\hline Carbonic oxide $(\mathrm{CO})$ & $\cdots$ & $\cdots$ & $-139 \cdot 5$ & 355 & $-190^{\circ} 0$ & $-207^{\circ} \mathrm{O}$ & 100 & $14{ }^{\circ} \mathrm{O}$ & $\stackrel{?}{A \text { bout }}$ & , \\
\hline Argon $\left(A_{1}\right)$ & $\cdots$ & $\cdots$ & $-12 I^{\circ} 0$ & $50^{\prime} 6$ & $-187^{\circ} \mathrm{O}$ & -1896 & $?$ & $19^{\circ} 9$ & $1 \cdot 5$ & , \\
\hline Oxygen $\left(\mathrm{O}_{2}\right) \quad \ldots$ & $\cdots$ & $\cdots$ & $-118 \cdot 8$ & $50 \cdot 8$ & $-182 \cdot 7$ & $?$ & $?$ & $16 \cdot 0$ & $r \cdot 124$ & Bluish. \\
\hline Nitric oxile (NO) & $\cdots$ & $\cdots$ & -93.5 & $71 \cdot 2$ & $-153 \cdot 6$ & -1670 & 138 & $15^{\circ} \mathrm{O}$ & $?$ & Colourless. \\
\hline Methane $\left(\mathrm{CH}_{4}\right)$ & $\cdots$ & $\cdots$ & $-8 I \cdot 8$ & $54 \cdot 9$ & $-164^{\circ} 0$ & $-185 \cdot 8$ & 80 & $8 \cdot 0$ & 0415 & " \\
\hline
\end{tabular}

The mean of the seven estimations of the critical temperature is $-12 \mathrm{I}^{\circ}$, and this may be taken as the critical temperature of argon.

The vapour prescures at ten temperatures from - 128.6 to $139^{\circ}$ I were also determined.

Determination of the Boiling and Freeing Points.

Two hundred cubic centimetres of liquid oxygen, prepared in my large apparatus, ${ }^{2}$ was poured into a glass vessel with

1 Abstract of a paper by Dr. K. Olszewski, Professor of Chemistry in the University of Crarow.

Walletin international de l'Acadentic de Cracorie, June $\times 890$; also Wiedemann's Beiblätter, vol. r5, p. 29.

No. $13: 9$, vOL. 51$]$
As can be seen from the foregoing table, argon belongs to the so-called "permanent" gases, and, as regards difficulty in liquefying it, it occupies the fourth place, viz. between carhon minoxide and oxygen. Its behaviour on liquefaction places it nearest to oxygen, but it differs entirely from oxygen in being solidifiable: as is well known, oxygen has not yet been made to assume a solid state.

The high density of argon rendered it prohable that its liquefaction would take place at a higher temperature than that

${ }^{3}$ I have re-determined the boiling point of oxygen. using large quantities of oxyzen, and a hydrogen thermometer of much larger dimensiuns than previousiy. The registered temperature is $I^{\circ} \cdot 3$ lower than that which I prevreviousiy. The 
at which oxygen liquefies. Its unexpectedly low critical temperature and boiling point seem to have some relation to its unexpectedly simple molecular constitution.

After the reading of the three foregoing papers, a discussion followed, of which we give the most important parts.

Dr. H. E. Armstrony said that the case for the existence of the new constituent was undoubtedly a very strong one, and would, no doubt, meet with very considerable criticism throushout the world. But, apart from the facts which were brought forward, there was a portion which was of a wildly speculative character : viz. the portion dealing with the probable nature of this new element. Apparently the authors were not entirely satisfied with the evidence to be adduced from the application of the Clausius method for the determination of the atomicity of the gas. It was quite conceivable that the condition which Prof. Ramsay pointed out as being the only alternative to the one which was apparently accepted by the authors of the communication, is a conceivable condition. It was quite likely that the two atoms existed so firmly locked in each other's embrace, that there was no possibility for them to take notice of anything outside, and that they were perfectly content to roll on together without taking up any of the energy that is put into the molecule. The spectroscopic evidence was not sufficient to justifv the conclusion that the new gas was a mixture. The great difficulty in accepting the conclusion that the gas was an element having a molecular weight of 40 , and an at mic weight of 40 , arose frum the difficulty of placing an element of that kind. All these matters, however, would have to be discussed later on more fully : they were matters which could only be discussed very gradually, as more $u$ as learned about the new substance.

Prof. A. W. Riucker said that the one cerlain fact which came out indisputably from the facts described by Prof. Ramsay was, that in spi'e of the doubt which may have existed on the ma'ter for the last few weeks or months, it was certain that they hat now a new cons'itucnt of the atmosphere. It seemed to him that one of the most interesting results arrived at from the physical point of view was the fact that the gas $w$ as monatomic, arguing from the determiner ratio of the specific heats. The experiments carried ont by Lord Rajleigh and Prof. Ramsay made it certain that the element had the particular ratio of specific heats mentioned. Well, then the question arose, What followed from this? In order that this ratio might be obtanned it was necessary that the atom with which they were dealing should be regarded as spherical. In conclusion, he said that whatever the effect might he upon the great chemical generalisation of Mendeléeff, that was, after all, an empirical law based at present upon no dynamical foundation. If it held its own in this case, it would, of course, strengthen the belief in it, but, on the other hand, the law did not stand on the footing of those great mechanical generalisations which could not be upset without upsetting the whole of our fundamental notions of science.

Prof. Roberts Austen remarked that in the Bessemer process alone some ten tons of iron were put into a vessel called a converter. During the conversion no less than 100,000 cubic feet of air passed through the fluid iron. Therefore Iooo cubic feet of argon went somewhere. He had taken Bessemer-blown metal which had not been treated with ferro-manganese, and pumped out forty times its volume of gas, of which one-twentieth was nitrogen. In that nitrogen he had not been able to detect any argon that could not have come from the water which was necessarily used in the manipulation. It remained to be seen whether the argon found its way into the iron, and if it stayed there, whether certain peculiarities that made Bessemer metal different from other kinds of steel could be traced to some of this 1000 cubic feet of argon, which had either passed into the air or into the iron.

Lord Rayleigh, in the course of his remarks, referrecl to the argument in favour of the monatomicity of the gas. Of course, what was directly proved by the experiment was that the whole, or nearly the whole, of the energy put into the gas, when it was heater, was devoled to increasing the energy of its translatory motion, and that no margin remained over to be attributed to intermolecular or interatumic motion. At first sight it seemed rather a strange thing that there should be no rotation in the molecules of the gas. That condition was met by the suggestion which had been put forward, and which had also been cimmunicated by Prof. Fitzgerald, in the fullowing words: "The reason why the ratio of specific heats of $I \cdot 66$ is sup. posed to prove monatomicity in a gas is because in a monatomic gas there are no internal motinns of any consequence. Now, if the atoms in a mulerule are so bound together that hardly any internal motions exist, it wou'd, so far as specific heat is concerned, behave like a monatomic element. That the atoms in argon may be very closely connectel seems likely from its very $\mathrm{g}$ eat chemical inertness. Hence the conclusion from the ratio of its specific heats may be, not that it is monatomic, hut that its atoms are so bound together in its molecule that the molecule behaves as a whicle as it it was monalomic." It was difficult to conceive the possibılity of such an eccentrically-shaped atom as that to move ahout without acquiring a considerable energy of rotation. He therefore thought that the only interpretation was that the gas was monatomic.

Lord Kelvin remarked as to the condition under which the ratio of the specific heats could be exactly $\mathbf{1} \cdot 66$, that he did not admit that a spherical atom cuuld fulfil that condition. A spherical atom would not be absolutely smooth. In other words, it must be a Boscovitch point. In fact, the only kind of atom that could be conceived as giving, in the dynamical theory of heat, rigorously the ratio I. 66 for the specific heat, was the ideal Boscuvitch mathematical point endowed with the property of inertia, and with the other property of acting upon neighbouring points with a force depending upon distance.

\section{UNIVERSITY AND EDUCATIONAL INTELLIGENCE.}

OXFORD. - A meeting was held on Monday last, in the rooms of the Regius Professor of Medicine, at the University Museum, and was attended by all the scientific professors and teachers of the University, with the exception of one or two, who, being unable to be present, expressed their concurrence by letter. It was unanimously resolved that a memorial connecling Sir Heniy Acland's name in a permanent manner with the (Iniversity Museum should be established. Sympathy was generally expresstd with the scheme already before the public, but it was felt that a more distinctly personal memorial in the Museum was desirable. The future consideration of the proposal will be the subject of a stcond nueeting to be held shortly.

Mr. A. Trevor Battye delivered a lecture before the Ashmolean Society, on Monday last, entitled "Ice-bound in Kolgnev." The lecturer narrated his personal experiences, and gave an account of the manners and customs of the Samoyedi, illustrated by numerous lantern-slides and specimens, and he also described the ornithological features of the island.

The Sibthorpian Professor of Rural Economy, Mr. R. Warington, F.R.S., gave his inaugural lecture to a large andience in the University Museum on Monday afternoon. The : ubject chosen was "The Present Relalions of Agricultural Art and Natural Science." He deplored the want of really good agricultural and horticultural libraries.

CAMBridge. - The election to the Sadlerian Professorship of Pure Mathematics, vacant by the dealh of Prof. Cayley, will be held on Munday, Fehruary 25, at 2.30 p.m. The names and testimonials of candidates are 10 be sent to the Vice Chancellor by Monday, February 18. The electors are the ViceChancellor (Mr. Austen Lei, h) , Dr. Phear, Dr. Ferrers, Dr. Taylor, Sir G. G. Stokes, Sir R. S. Ball, and Prof. G. H. Darwin.

The Observatory Syndicate propose the appointment of a Second Assistant Observer, at a :tipend of $£ 100$ a year. The appointment will be for five years, and will be made by the Director, with the consent of the Vice-Chancellor.

\section{SCIENTIFIC SERIALS.}

American Meteorological Journal, January.-Solar mag. netism in meteorology, by Prof. F. H. Bigelow. This article contains some general remarks on the present state of the problems arising out of the relations that have been traced by the author's study of solar magnetism and its influences upon meteorological phenomena. Prof. Bigelow endeavours to show that the u-ually accepted mode of propagation of energy from the sun to the earih is not the only one that exists, and suggests that another possible mode is due to polarised solar magnetic force, such as surrounds a magnet. $T$ he progress of the investigation was made is three distinct stage: : (I) the detection of the true period of the sun's rotation; (2) the determination of NO. 1319 . VOL. 517 